\title{
Interlaminar damage of carbon fiber reinforced polymer composite laminate under continuous wave laser irradiation
}

\author{
Yan-Chi Liu ${ }^{\mathrm{a}, \mathrm{b}}$, Chen-Wu Wu ${ }^{\mathrm{a}, *}$, Yi-Hui Huang ${ }^{\mathrm{a}, \mathrm{b}}$, Hong-Wei Song ${ }^{\mathrm{a}}$, Chen-Guang Huang ${ }^{\mathrm{a}}$ \\ a Institute of Mechanics, Chinese Academy of Sciences, Beijing 100190, China \\ ${ }^{\mathrm{b}}$ School of Physics, University of Chinese Academy of Sciences, No. 19A Yuquan Road, Beijing 100049, China
}

\section{A R T I C L E I N F O}

\section{Article history:}

Received 18 February 2016

Received in revised form

8 July 2016

Accepted 5 August 2016

Keywords:

Laminates

Damage

Continuous wave laser

Finite element analysis (FEA)

\begin{abstract}
A B S T R A C T
The interlaminar damages were investigated on the carbon fiber reinforced polymer (CFRP) composite laminate under laser irradiation. Firstly, the laminated T700/BA9916 composites were exposed to continuous wave laser irradiation. Then, the interface cracking patterns of such composite laminates were examined by optical microscopy and scanning electron microscopy. Finally, the Finite Element Analysis (FEA) was performed to compute the interface stress of the laminates under laser irradiation. And the effects of the laser parameters on the interlaminar damage were discussed.
\end{abstract}

(c) 2016 Elsevier Ltd. All rights reserved.

\section{Introduction}

The widely application of the carbon fiber reinforced polymer (CFRP) laminates in the aircrafts requires accurate structure designing and reliable part manufacturing [1-5]. The laser beam is a promising machining tool for CFRP composite processing as it is always accompanied with better quality and higher productivity. It can also be utilized in processing the small and complex parts due to the fact the beam spot could be very accurately refined and heating affect zones be largely constrained. Besides, the laser machining is of lower cost in comparison to other techniques such as milling shape cutting and water jet-cutting [6,7].

However, laser machining might also has some noticeable size effects as it develops a local temperature elevation in the CFRP laminates [8]. As we know, the composite gradients are always combustible and the CFRP laminates are susceptible to deterioration in mechanical properties when exposed to the high temperature atmosphere $[9,10]$. Therefore, the present laser machining of the CFRP composites, which is based on the physical and chemical actions such as pyrolysis and ablation, would induce thermal damage in the CFRP laminate beyond the objective regions $[11,12]$. Among all of the probable thermal damages, the interlaminar damage is of most important effects as the large scale interlaminar cracking would lead to catastrophic results in the

\footnotetext{
* Correspondence to: Institute of Mechanics, Chinese Academy of Sciences, No. 15 Beisihuan Xi Road, Beijing 100190, China.

E-mail addresses: chenwuwu@imech.ac.cn, c.w.wu@outlook.com (C.-W.Wu).

CFRP laminate structures. That's also why much research have been focused on the interlaminar damage during various thermomechanical process of CFRP parts.

Theoretically speaking, the interlaminar separation in the CFRP laminates is dominated by the evolution of the interlaminar damages, in particular the propagation of the interlaminar cracks. It was revealed that the fiber lay angle influences greatly the propagation of the interlaminar cracks [13]. And the relative weak fiber-matrix interface would contribute greatly to the multi-interlaminar shear failure mode [14]. Moreover, some fracture mechanics experimental work were carried out on the CFRP laminates under different temperature environment and it has been revealed that the apparent interlaminar strength would be reduced with the temperature elevation [15-20]. Recently, a few methods have been developed to enhance the interlaminar strength and improve the overall interlaminar performance of the CFRP laminates [21-23]. While, to describe correctly the interlaminar behaviors of the CFRP laminates under laser irradiation should be the important prerequisite for any possible optimization in designing or manufacturing of the CFRP composite materials as far as the processing performances are taken into account.

In the present work, firstly, the interlaminar damage morphology of the CFRP laminate specimens under continuous laser irradiation was observed by optical microscopy as well as scanning electron microscopy. Then, the interlaminar damage pattern was analyzed and its space distribution characteristic was discussed. Finally, a finite element model was set up to calculate the temperature, deformation and stress arising in the CFRP laminates 
during laser irradiation.

\section{Experimental description and results}

The sixteen $0.125 \mathrm{~mm}$ thick CFRP laminae are stacked via the ply sequence of $\left[45^{\circ}, 0^{\circ},-45^{\circ}, 90^{\circ}\right]_{2 \mathrm{~s}}$ to produce the $2 \mathrm{~mm}$ thick CFRP laminate used in the laser irradiation test as shown in Fig. 1. The size of the specimen is $50 \mathrm{~mm} \times 50 \mathrm{mmx} 2 \mathrm{~mm}$. The autoclave cured CFRP lamina is composed of ccf700 carbon fiber and BA9916-II resin matrix. The effective density of the CFRP laminate is $145 \pm 5 \mathrm{~g} / \mathrm{m}^{3}$.

The specimen is placed in a cabinet full of Nitrogen with a transparent window, through which the Laser beam enters and impinged at the specimen vertically. Geometrically, the axial plane of the laminate specimen is parallel to the laser beam direction. The continuous wave laser of wavelength $1070 \mathrm{~nm}$ was used in the experiments. The laser beam is focused on the front most surface of the specimen and the initial spot radius is about $5 \mathrm{~mm}$. Of course, the spot radius will slightly change with the removal of the surface material as the static irradiation is adopted in the present experiment. The irradiation holds for $3 \mathrm{~s}$ under different output laser powers, which are typically $500 \mathrm{~W}, 800 \mathrm{~W}$ and $1000 \mathrm{~W}$.

After being irradiated by the Laser, the specimens were split along the axial plane of the irradiation spot to reveal the cross section. The cut sections of the laminates were polished and the specimens were ultrasonic cleaned to show the cracks clearly. The optical microscope and scanning electron microscope were used to observe the section morphology, in particular the interface damages.

The typical cross section morphologies by optical microscope are shown in Fig. 2. It is revealed that the obvious pyrolysis happed in the irradiated region of the specimens, and the interlaminar cracks could be found close to the backward surface other than the irradiated forward surface.

Fig. 2 also reveals fiber fracturing in the surface layer directly irradiated and the pyrolysis could be observed in up to eight

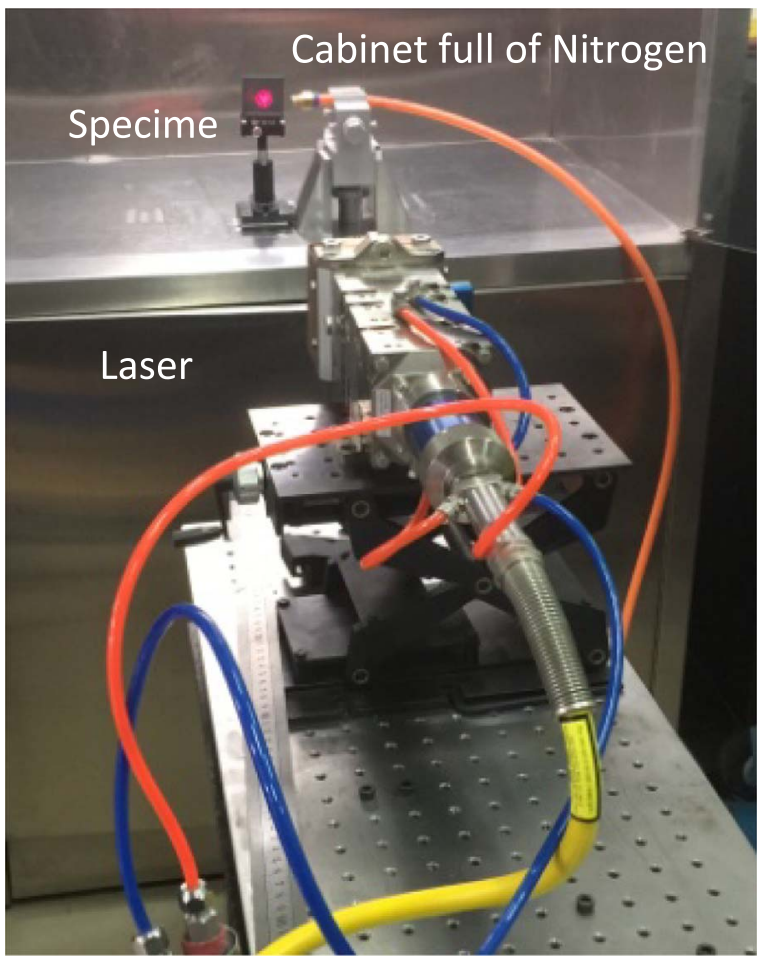

Fig. 1. The experimental setup.
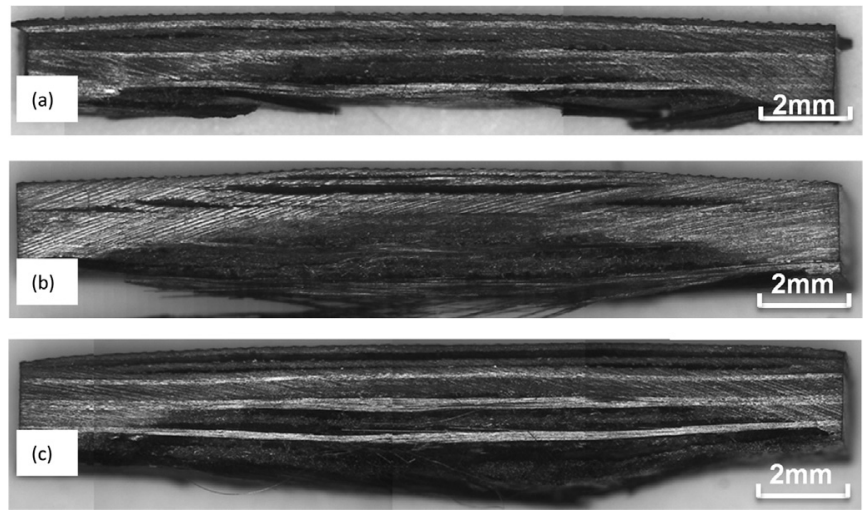

Fig. 2. Cross section for the cases of laser power (a) $500 \mathrm{~W}$, (b) $800 \mathrm{~W}$ and (c) $1000 \mathrm{~W}$

laminae counted from the forward surface layer. Moreover, it is shown that several layers of carbon fiber remained even after the matrix removed by the laser irradiation. To reveal further characteristics of the interface damages in the specimen, the cross section morphology observed by scanning electron microscope are shown in Fig. 3 and 4. The interface cracks, indicated by black lines and the pyrolysis front edge, indicated by red lines are further sketched in Fig. 5 to reveal clearly their locations and geometrical characteristics. The distinctive line widths are intentionally chosen in the sketch to approximately represent the opening displacement of the interlaminar cracks. The crack of maximum opening displacement, which always appears at the center of the pennyshaped cracks, than the half thickness of a single lamina is simply named as coarse crack in the manuscript, otherwise as fine crack. According to the experimental observation, the location of the most coarse crack and the pyrolysis front edge would move to the backward surface were the laser power increased, which is also sketched in Fig. 5. Of course, the crack opening displacement should be intrinsically related to the thermal strain and thermal stress developed in the specimen. The out-of-plane deformation of the laminate contributes largely to the opening displacement of the interlaminar cracks, which is directly resulted from the asymmetric thermal expansion of the laminates.

It is indicated in Fig. 3(a), Figs. 4(a) and 5(a) that the primary interface crack arises at the middle depth location of the laminate, i.e. between the fourth laminae and the fifth laminae counted from the backward surface for the case of laser power $500 \mathrm{~W}$. The primary crack locates at the second interface for the case of laser power $800 \mathrm{~W}$ as shown in Figs. 3(b), 4(b) and 5(b) and the first interface for the case of Laser power $1000 \mathrm{~W}$ as shown in Figs. 3(c), 4(c) and 5(c). It looks like that the location of the primary cracks approaches to the backward surface were the laser power increased. This is also the case for the pyrolysis front edge as demonstrated in Fig. 5. Moreover, it is indicated that the interlaminar cracks would be widened and lengthened by increasing the output laser power, which is similar to the phenomenon observed in carbon/carbon composite subjected to elevated temperature [24]. It is also noteworthy that there are always short cracks arising close to the backward surface for almost all of the specimens irradiated by different laser powers, while as the irradiation by higher output laser power might have been more capable in changing the small cracks into primary coarse cracks.

The numerical analysis was conducted based on Finite Element Method (FEM) to preliminarily demonstrate the thermo-mechanical responses of the CFRP laminates under the irradiation of continuous wave laser. In particular, the interface stresses between adjacent laminae responsible for the interlaminar damages are investigated. 

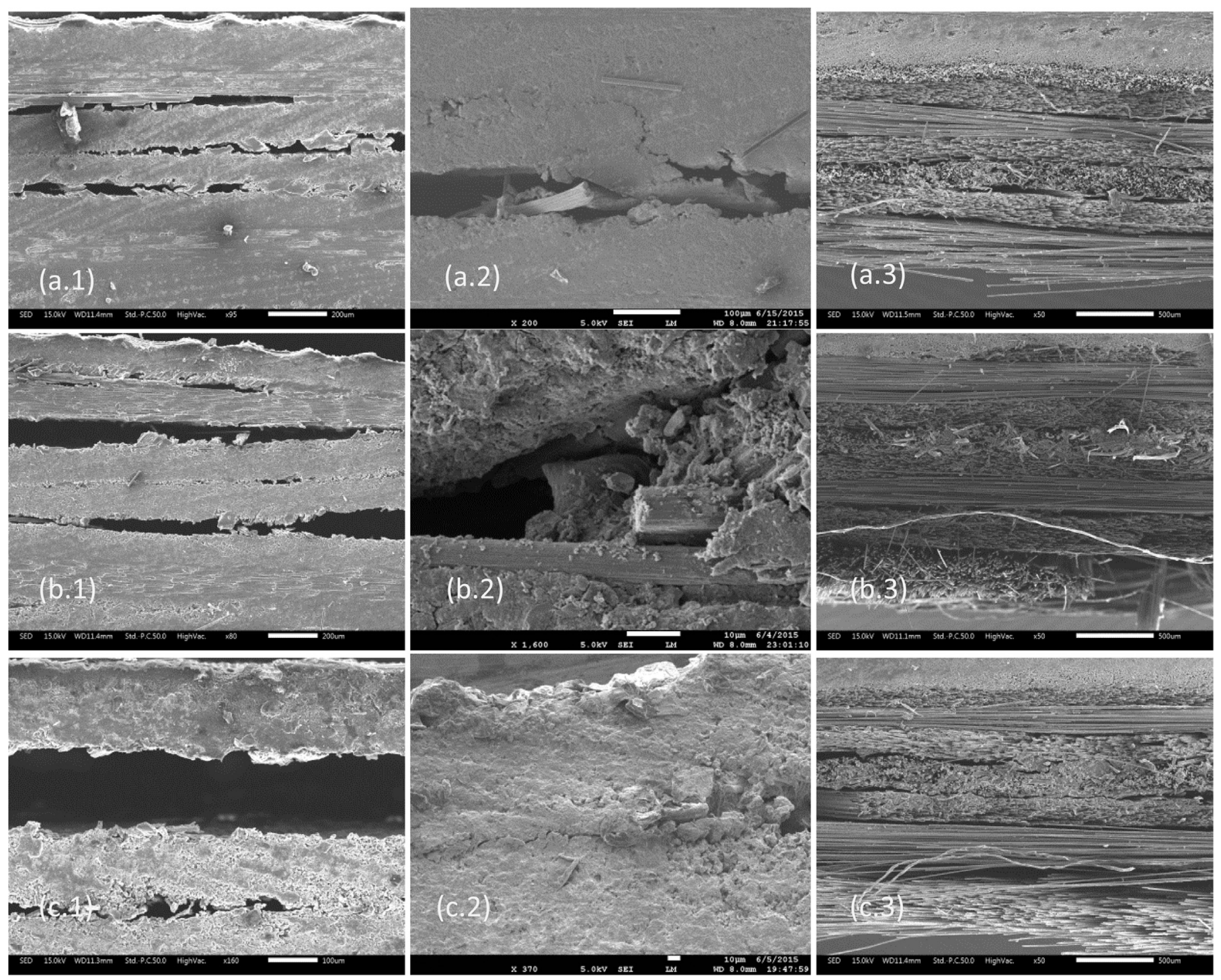

Fig. 3. Interface fracture for the case of laser power (a) $500 \mathrm{~W}$, (b) $800 \mathrm{~W}$ and (c) $1000 \mathrm{~W}$.

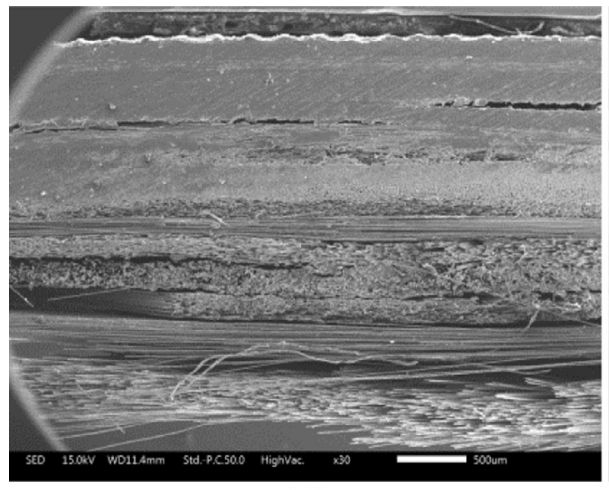

(a)

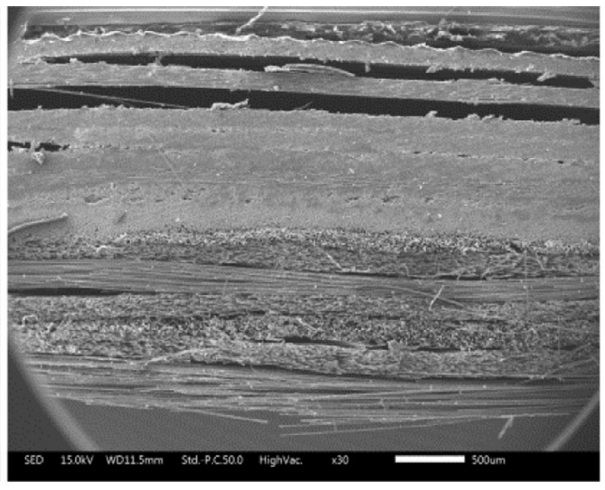

(b)

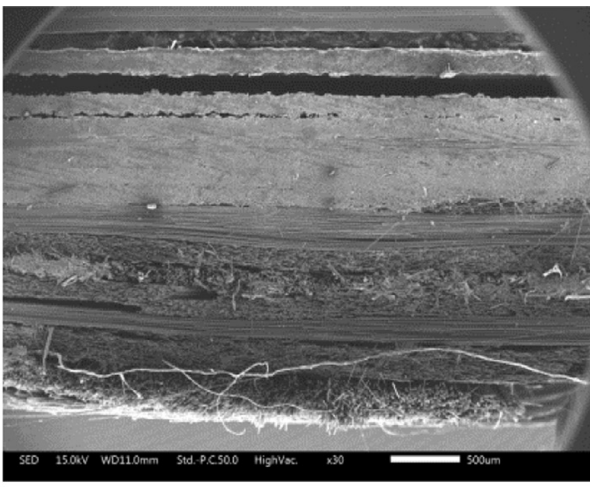

(c)

Fig. 4. Interface fracture for the case of laser power (a) $500 \mathrm{~W}$, (b) $800 \mathrm{~W}$ and (c) $1000 \mathrm{~W}$.

\section{Finite element model and results}

The finite element method was used to analyze the temperature and the thermal stress arising in the CFRP laminated plates under laser irradiation. The technique of coupling and decoupling the Degree of Freedom (DOF) [25] was further utilized to simulate the interlaminar cracking in the laminates, in which the pre-coupled degree of freedom of the nodes at the interfaces would be decoupled once the stress states meet some fracture criterion. The quarter geometry of the CFRP laminated by laser irradiation is modeled in the computation as shown in Fig. 6 by considering the symmetry of the object. The overall dimensions of the quarter 


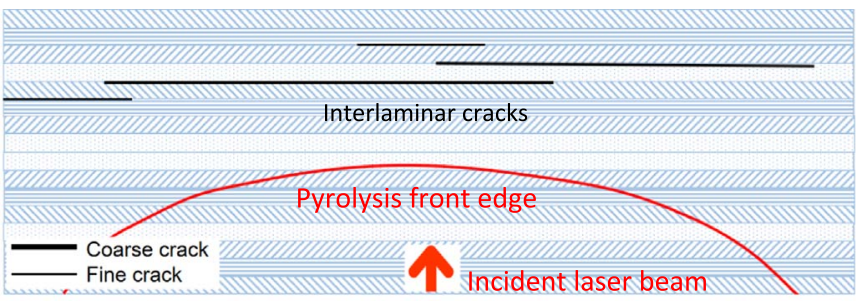

(a) For the case of laser power $500 \mathrm{~W}$

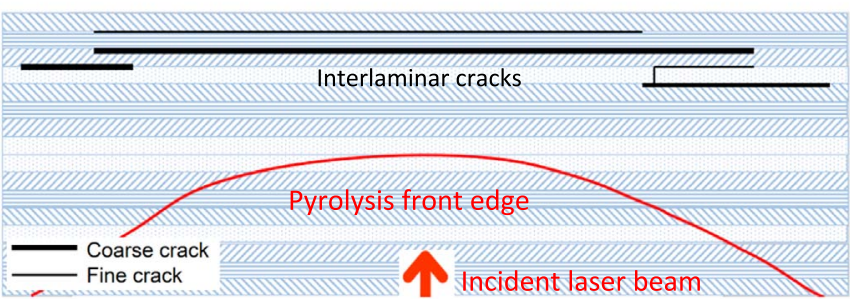

(b) For the case of laser power $800 \mathrm{~W}$

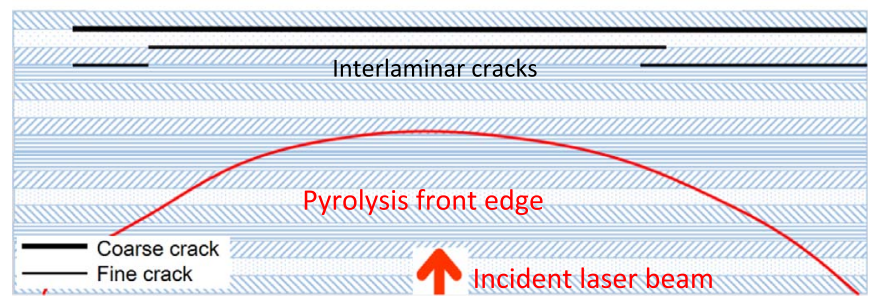

(c) For the case of laser power $1000 \mathrm{~W}$

Fig. 5. The sketch of the interlaminar cracks and pyrolysis front edge. (a) For the case of laser power $500 \mathrm{~W}$. (b) For the case of laser power $800 \mathrm{~W}$. (c) For the case of laser power $1000 \mathrm{~W}$.

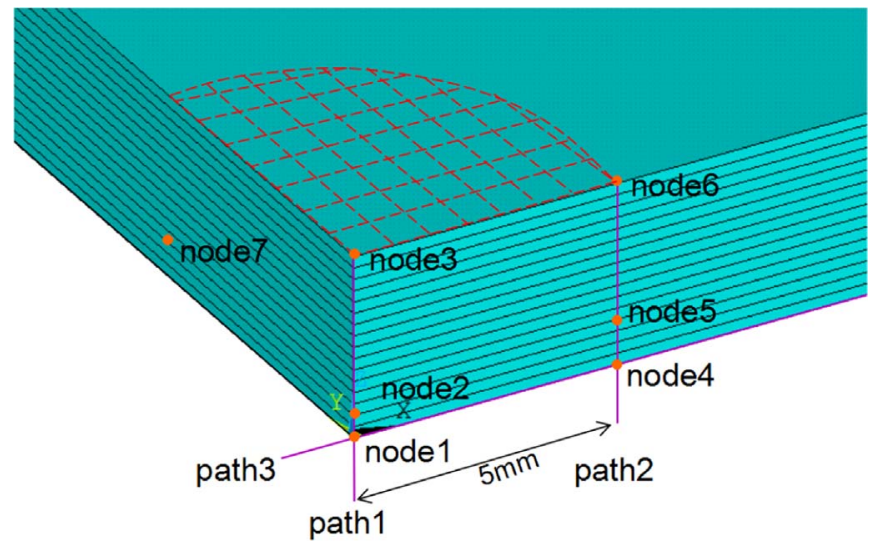

Fig. 6. Geometry model and projection path diagram.

Table 1

The Coordinates of the specific nodes.

\begin{tabular}{llllllll}
\hline Node & 1 & 2 & 3 & 4 & 5 & 6 & 7 \\
\hline $\mathrm{X} / \mathrm{mm}$ & 0 & 0 & 0 & 5 & 5 & 5 & 0 \\
$\mathrm{Y} / \mathrm{mm}$ & 0 & 0 & 0 & 0 & 0 & 0 & 0.5 \\
$\mathrm{Z} / \mathrm{mm}$ & 0 & 0.25 & 2 & 0 & 0.5 & 2 & 0.5 \\
\hline
\end{tabular}

model are $50 \mathrm{~mm} \times 50 \mathrm{~mm} \times 2 \mathrm{~mm}$. The laminae are discretized with consistent element sizes and the spatially coincident nodes at the interfaces between adjacent laminae are initially coupled to represent the continuous interfaces, which would transfer heat as well as forces between the adjacent laminae before cracking. The laser beam covered area indicated by dot lines in Fig. 6 is located on the forward surface plane $z=2 \mathrm{~mm}$. The ply sequence is [ $45^{\circ}$, $\left.0^{\circ},-45^{\circ}, 90^{\circ}\right]_{2 s}$ and the thickness of each single layer is
Table 2

The location descriptions on the specific paths.

\begin{tabular}{ll}
\hline Path & Descriptive equation \\
\hline$\# 1$ & $\mathrm{X}^{2}+\mathrm{y}^{2}=0,0 \leq \mathrm{Z} \leq 2$ \\
$\# 2$ & $(\mathrm{X}-5)^{2}+\mathrm{y}^{2}=0,0 \leq \mathrm{Z} \leq 2$ \\
$\# 3$ & $\mathrm{Y}^{2}+\mathrm{Z}^{2}=0,0 \leq \mathrm{X} \leq 50$ \\
\hline
\end{tabular}

Table 3

Temperature dependent thermo-mechanical properties of the lamina.

\begin{tabular}{lllllll}
\hline $\mathrm{T}\left({ }^{\circ} \mathrm{C}\right)$ & $\mathrm{E}_{1}(\mathrm{GPa})$ & $\mathrm{E}_{2}(\mathrm{MPa})$ & $\mathrm{G}(\mathrm{MPa})$ & $\begin{array}{l}\alpha_{1} \\
\left(10^{-6} /{ }^{\circ} \mathrm{C}\right)\end{array}$ & $\begin{array}{l}\alpha_{2} \\
\left(10^{-6} /{ }^{\circ} \mathrm{C}\right)\end{array}$ & $\mathrm{C}\left(\mathrm{J} /\left(\mathrm{kg}{ }^{\circ} \mathrm{C}\right)\right)$ \\
\hline 0 & 121.3 & 9650 & 3385.5 & 4 & 40 & 1140 \\
100 & 113.7 & 1036.4 & 398.6 & 4 & 40 & 821.2 \\
200 & 109.5 & 433.0 & 166.5 & 4 & 40 & 821.2 \\
300 & 103.7 & 119.8 & 46.1 & 4 & 40 & 818.3 \\
400 & 0.01 & 10 & 1.6 & 4 & 40 & 1140 \\
1000 & 0.01 & 10 & 1.6 & 4 & 40 & 1140 \\
\hline
\end{tabular}

$\mathrm{t} \_\mathrm{sl}=0.125 \mathrm{~mm}$. The orthotropic constitutive relationship was assumed for every single layer. The coordinates of the specific nodes are listed in Table 1 and the location descriptions on the specific paths listed in Table 2.

The main temperature dependent thermo-mechanical parameters of the materials are listed in Table 3. In Table 3, T is temperature; $E_{1}$ the elastic modulus in the direction parallel to the fiber, $E_{2}$ vertical to the fiber; $G$ the shear modulus; $\alpha_{1}$ the thermal expansion coefficient in the direction parallel to the fiber, $\alpha_{2}$ vertical to the fiber and $C$ the specific heat capacity. As partially revealed by Fig. 2, the possible negative thermal expansion $[26,27]$ effect looks like be concealed in the experimental observation by the soft porous bump developed in the decomposed region wherein the maximum temperature was above the pyrolyzation temperature of the epoxy matrix. Therefore, the constant thermal expansion coefficients were assumed in the computation to manifest the bumping morphology. However, it is self-evident that such treatment on the thermal expansion effect should not influence obviously the overall stress and deformation in the region away from the decomposed material as the elastic modulus of the decomposed material is very small as shown in Table 3. Besides, the temperature independent density of the material is $1590 \mathrm{~kg} /$ $\mathrm{m}^{3}$, Poisson's ration is 0.3 and the in-plane thermal conductivity and normal thermal conductivity of each lamina are $\mathrm{K}_{1}=5.223 \mathrm{~W} /$ $(\mathrm{m} \mathrm{K})$ and $\mathrm{K}_{2}=0.725 \mathrm{~W} /(\mathrm{m} \mathrm{K})$, respectively.

The laser beam of radius $r_{-} b=5 \mathrm{~mm}$ was modeled to normally irradiate the CFRP laminate, for which the spot region on the specimen was indicated by dot lines in Fig. 5. The total incident power $500 \mathrm{~W}, 800 \mathrm{~W}$ and $1000 \mathrm{~W}$ are analyzed and the surface heat flux $6.37 \times 10^{6} \mathrm{w} / \mathrm{m}^{2}, 10.19 \times 10^{6} \mathrm{w} / \mathrm{m}^{2}$ and $12.74 \times 10^{6} \mathrm{w} / \mathrm{m}^{2}$ are applied onto the dot line covered area for the three cases. The transient heat conduction equation was solved numerically

$\rho C_{p} \frac{\partial T}{\partial \mathrm{t}}=\nabla \cdot(k \nabla T)$

with the convective heat transfer $q_{c}$ and radiative heat transfer $q_{r}$ being applied onto the relevant surface boundaries.

$\mathrm{q}_{\mathrm{c}}=\mathrm{h}\left(\mathrm{T}-\mathrm{T}_{\mathrm{en}}\right)$,

and

$\mathrm{q}_{\mathrm{r}}=\varepsilon \sigma \mathrm{T}^{4}$,

where the operator 
$\nabla=\frac{\partial}{\partial \mathrm{x}_{1}}+\frac{\partial}{\partial \mathrm{x}_{2}}+\frac{\partial}{\partial \mathrm{x}_{3}}$,

with $\mathrm{x}_{1}, \mathrm{x}_{2}$ and $\mathrm{x}_{3}$ representing $\mathrm{x}, \mathrm{y}$ and $\mathrm{z}$.

$\rho$ is the density,

$\mathrm{C}_{\mathrm{p}}$ is the specific heat capacity,

$\mathrm{T}$ is the temperature,

$\mathrm{t}$ is the time,

$\mathrm{k}$ is the thermal conductivity,

$\mathrm{T}_{\mathrm{en}}=293 \mathrm{~K}$ is the environment temperature,

$\mathrm{h}=30 \mathrm{Wm}^{-2} \mathrm{~K}^{-1}$ is the natural convection heat transfer coefficient,

$\varepsilon=0.8$ is the surface emissivity and

$\sigma=5.67 \times 10^{8} \mathrm{Wm}^{-2} \mathrm{~K}^{-4}$ is the Stephan Boltzmann constant.

Once the temperature field has been obtained at any instant, the deformation and thermal stress could be calculated via solving the quasi-static equilibrium equations within the discretized domain

$\Delta u_{i}+\frac{1}{1-2 v}\left(\frac{\partial u_{i}}{\partial x_{i}}\right)_{, i}=\frac{2(1+v)}{1-2 v} \alpha \theta_{, i} \quad i=1,2,3$

with the following displacement constraints being applied onto the symmetry plane and the far end boundaries

$\mathrm{u}_{\mathrm{x}}=0$ upon $\mathrm{x}=0$,

$\mathrm{u}_{\mathrm{y}}=0$ upon $\mathrm{y}=0$,

$\mathrm{u}_{\mathrm{z}}=0$ upon $\mathrm{x}=50 \mathrm{~mm}$ or $\mathrm{y}=50 \mathrm{~mm}$.

where the operator

$\Delta=\frac{\partial^{2}}{\partial x_{1}^{2}}+\frac{\partial^{2}}{\partial x_{2}^{2}}+\frac{\partial^{2}}{\partial x_{3}^{2}}$,

$\mathrm{u}$ is the displacement vector,

$\mathrm{v}$ is the Poisson's ration,

$\alpha$ is the thermal expansion coefficient,

$\theta$ is the temperature change and the subscript

' $i$ ' means the coordinates $\mathrm{x}, \mathrm{y}$ and $\mathrm{z}$,

', i' means the partial derivative to the coordinates $\mathrm{x}, \mathrm{y}$ and $\mathrm{z}$.

The numerical solutions to the heat conduction Eq. (1) and the piecewise quasi-static equilibrium Eq. (5) were achieved and the principle experimental phenomena, arising in the CFRP laminates subjected to the continuous wave laser irradiation, were demonstrated in the following section.

As far as the interfacial stresses meet the fracture criterion, like as that derived from the theory of maximum tensile, shear stress and equivalent stress, the DOF of the nodes at the interfaces would be decoupled and the uncoupled interlaminar nodes act as the free surfaces of the interlaminar cracks.

\section{The computational results and discussion}

The typical temperature and their gradient profiles at several specific instants, i.e. time $=3 \mathrm{~s}, 5 \mathrm{~s}$ and $7 \mathrm{~s}$ are shown in Fig. 7 and 8 for the case of laser power $800 \mathrm{~W}$.

One can find out that the maximum temperature within the irradiated area arises at the instant $3 \mathrm{~s}$, after then the laser irradiation was switched off and the maximum temperature would decrease apparently. Although the backward surface might have experienced further temperature increasing for some time after the laser was switched off due to the lag in heat conduction through the depth direction of the laminates. It is also indicated that the peak temperature appears at the center point while the maximum temperature gradient appear in the zones around the edge of the laser beam covered region.

To reveal the temperature evolution of the specimen, the temperature histories of specific nodes for the case of laser power $800 \mathrm{~W}$ are displayed in Fig. 9. The dependency of the temperature histories of the specific nodes, node 1, 3, 4 and 6 on the incident laser power are further shown in Fig. 10 (a), (b), (c) and (d).

It is validated that the maximum temperature of the node \#3 that located at the center of the forward surface covered by the laser spot arises at the instant of time $=3 \mathrm{~s}$, when the laser is to be switched off. The maximum magnitudes of the temperature of the other nodes appear later than $3 \mathrm{~s}$ because the inevitable delay in the heat conduction within the laminates. The temperature of the nodes at the forward surface change much more abrupt than that of the nodes at the backward surface as indicated in the history curves in Figs. 9 and 10, which is in consistent with the intuitive knowledge. Fig. 10 also shows that the increase in laser power would increase the temperature magnitudes but not change the characteristics of the temperature histories.

The temperatures are mapped onto the vertical path (path 1) and the horizontal path (path 3) as shown in Fig. 11 and 12, respectively. In detail, Figs. 11 (a) and 12 (a) provide the path mapping of the temperature at specific instants, while as Figs. 11 (b) and 12 (b) the path mapping of the temperature for the cases at instant $3 \mathrm{~s}$ with different incident laser power.

It is indicated that the temperature in the region around the forward surface would approach their maximum magnitudes at the instant when the laser irradiation was switched off. In comparison, the other regions would experience further temperature elevation after then. Moreover, one can find out that the increase in the incident laser power would increase the temperature
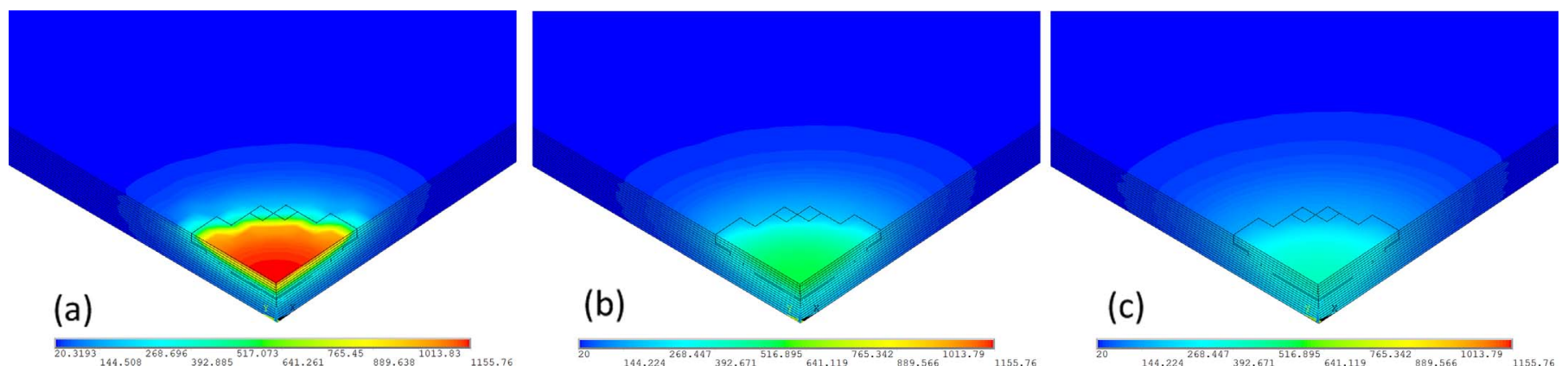

Fig. 7. Temperature profile $\mathrm{P}=800 \mathrm{~W}$ (a) $3 \mathrm{~s}$, (b) $5 \mathrm{~s}$, (c) $7 \mathrm{~s}$. 

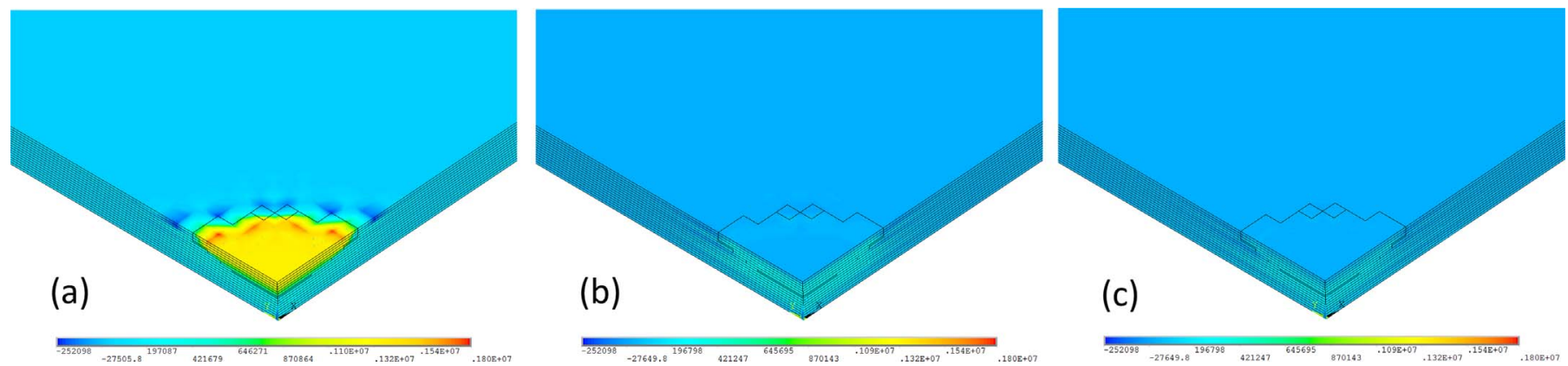

Fig. 8. Temperature gradient profile $P=800 \mathrm{~W}$ (a) $3 \mathrm{~s}$, (b) $5 \mathrm{~s}$, (c) $7 \mathrm{~s}$.

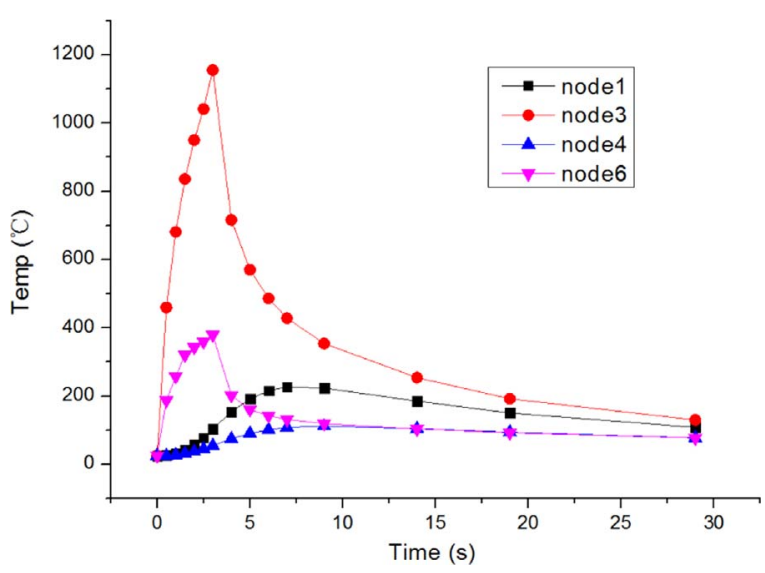

Fig. 9. Temperature histories of specific nodes for the case of $p=800 \mathrm{~W}$.

gradients in both the vertical direction and the horizontal direction as shown in Figs. 11(b) and 12 (b), respectively. The horizontal path mapping of the temperature in Fig. 11 also shows that the temperature elevation is mainly refined to the region of radius about twice the laser beam radius. That is, the temperature change is very slight about $\mathbf{r} \_b \times 2$ distant away from the center of the laser beam covered region.

Fig. 13 shows the total displacement profiles for the case of laser power $800 \mathrm{~W}$ at the instants time $=3 \mathrm{~s}, 5 \mathrm{~s}$ and $7 \mathrm{~s}$. From the geometrical view, the local bump of the decomposed materials is in consistent with the experimentally observed morphology. The out of plane deformation could be observed via magnifying the displacement vector field by about 50 times as the mass transfer is temporarily omitted in the simulation. The out of plane deformation is always thought to be responsible to the arising of normal interfacial tensile stress in a multilayer structure. Moreover, the high displacement gradient arise near the edge of the laser beam covered region, which would induce large shear stress therein.

Fig. 14 shows the profiles of the normal stress component along the $Z$ direction $S Z$ for the case of laser power $800 \mathrm{~W}$ at the instants time $=3 \mathrm{~s}, 5 \mathrm{~s}$ and $7 \mathrm{~s}$. Truly, the obvious normal tensile stresses appear at the interfaces between the adjacent laminae, which should have resulted in the interlaminar cracking of the specimen during test.

The histories of the normal stress component SZ on node 2, the shear stress component SXZ on node 5 and SYZ on node 7 are diagramed in Fig. 15 (a), Fig. 16 (a) and Fig. 17 (a). Correspondingly, the histories of the temperature and temperature gradient histories are graphed in Fig. 15 (b), Figs. 16 (b) and 17 (b). It is indicated in Fig. 15 (a), Fig. 16 (a) and Fig. 17 (a) that the normal stress SZ at node 2, the shear stress SXZ at node 5 and SYZ at node 7 all experience an abrupt increasing after the laser irradiation started and a gradual decrease after the laser irradiation stopped.
The peak magnitudes of these stress components appear at the instant several seconds after switching off the irradiation, which is in consistent with the relevant temperature histories as shown in Fig. 15 (b), Fig. 16 (b) and Fig. 17 (b). That is, the delay in the peak values of the temperature and temperature gradients on these nodes would accompanied with the delay in the peak stresses therein. As the thermal stress would be ultimately determined by the relevant temperature field as indicated by Eq. (4).

The normal stress component SZ mapped onto the vertical path 1 is shown in Fig. 18 (a) for the case of laser power $800 \mathrm{~W}$ at different instants. Fig. 18 (b) shows the stress component SZ at instant $7 \mathrm{~s}$ mapped onto the vertical path 1 for the cases of different laser powers. Fig. 18 (a) shows that the normal stress acted on the nodes at the central axis basically increases with time of range from $1 \mathrm{~s}$ to $7 \mathrm{~s}$, and after then decrease gradually. Fig. 18 (b) shows that the increase of the incident laser power would basically lead to the increase of the normal interlaminar stress. While a little deviation would arise around the forward surface of the specimen, in particular there exists obvious normal compressive stress near the forward surface at the instant time $=1 \mathrm{~s}$ as shown in Fig. 19 (a). Fig. 19 (b) also reveals that the normal stresses around the middepth of the specimen decease with the increase of the incident laser power. This is because the pyrolyzation volume, as shown in Fig. 19, increases with the increase of the incident laser power and more stress within the domain close to the pyrolyzation zone would be released.

The shear stress components SXZ and SZ at instant $7 \mathrm{~s}$ mapped onto the vertical path 2 is shown in Fig. 20 for the cases of different laser powers. Again, the shear stress component mapped onto the vertical path2 show that the maximum magnitude arises at the interfaces between the laminae around the backward surface of the specimen. All of the stress results explain why there are more large interlaminar cracks developed at the interface near the backward surface of the specimens in the experiments, which is similar to the so-called multi-interlaminar shear [28]. To be noted that there exists a maximum magnitude around the pyrolysis front edge for the normal stress SZ mapped onto path2 due to the free edge effect, although which is relatively small in comparison to that at the center around the backward surface as shown in Fig. 15. The interlaminar delamination could not necessarily be induced by such small tensile stress therein. However, it is revealed that the mode mixity of the interface stress is position dependent, which would influence the interlaminar damage status as the interface toughness relies on the mode mixity of loading.

The computational results also reveal that the maximum normal stress acted on the interface between the adjacent laminae is slightly higher than $20 \mathrm{MPa}$ and the maximum shear stress slightly higher than $25 \mathrm{MPa}$, which is about half of the interlaminar strength of the CFRP laminates measured in room temperature ambient [2]. Such difference indicates that the temperature elevation in service as well as heat treatment would greatly reduce the interlaminar strength of the CFRP laminates [13,16,22,28]. 

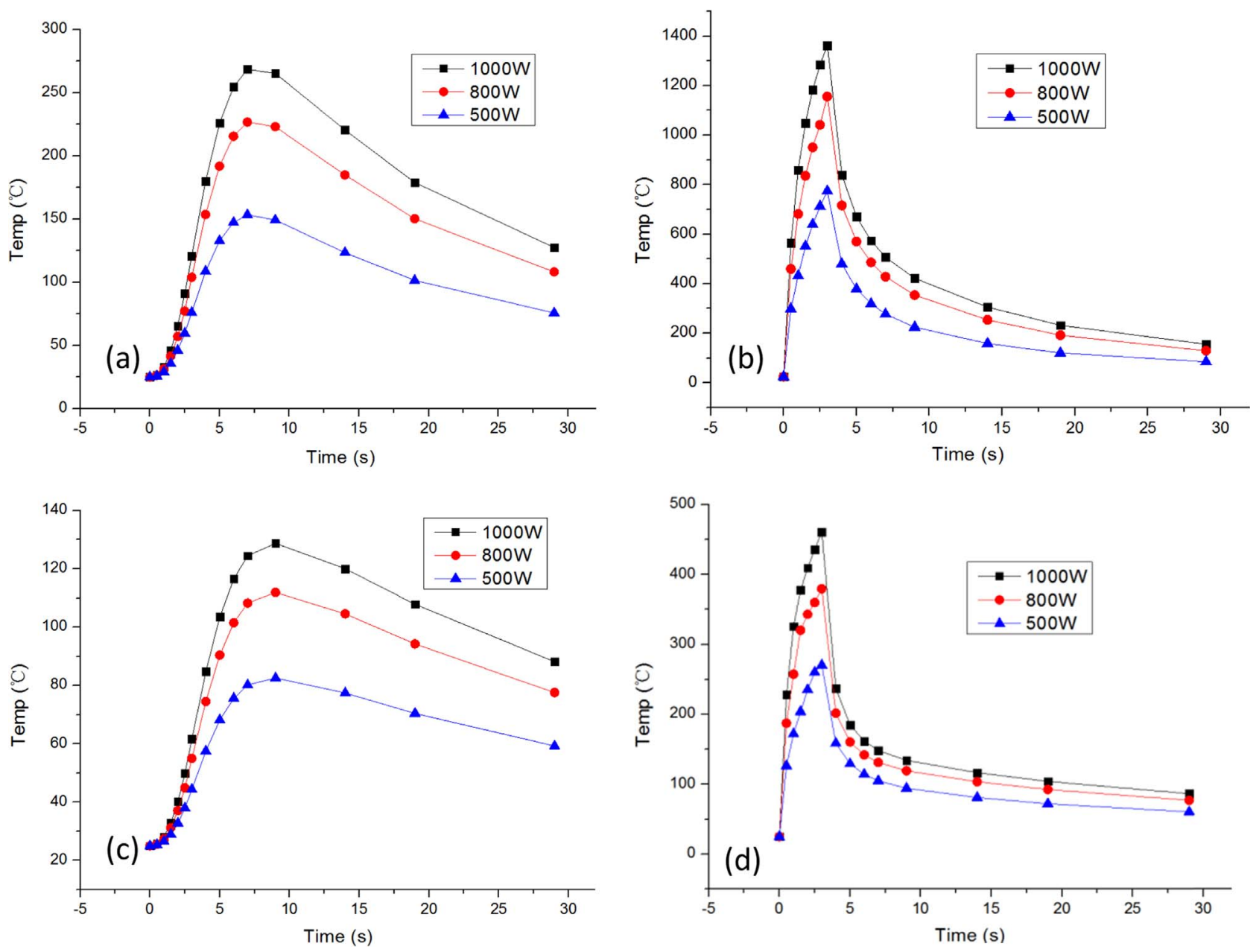

Fig. 10. Temperature history of (a) node 1, (b) node 3, (c) node 4 (d) node 6.
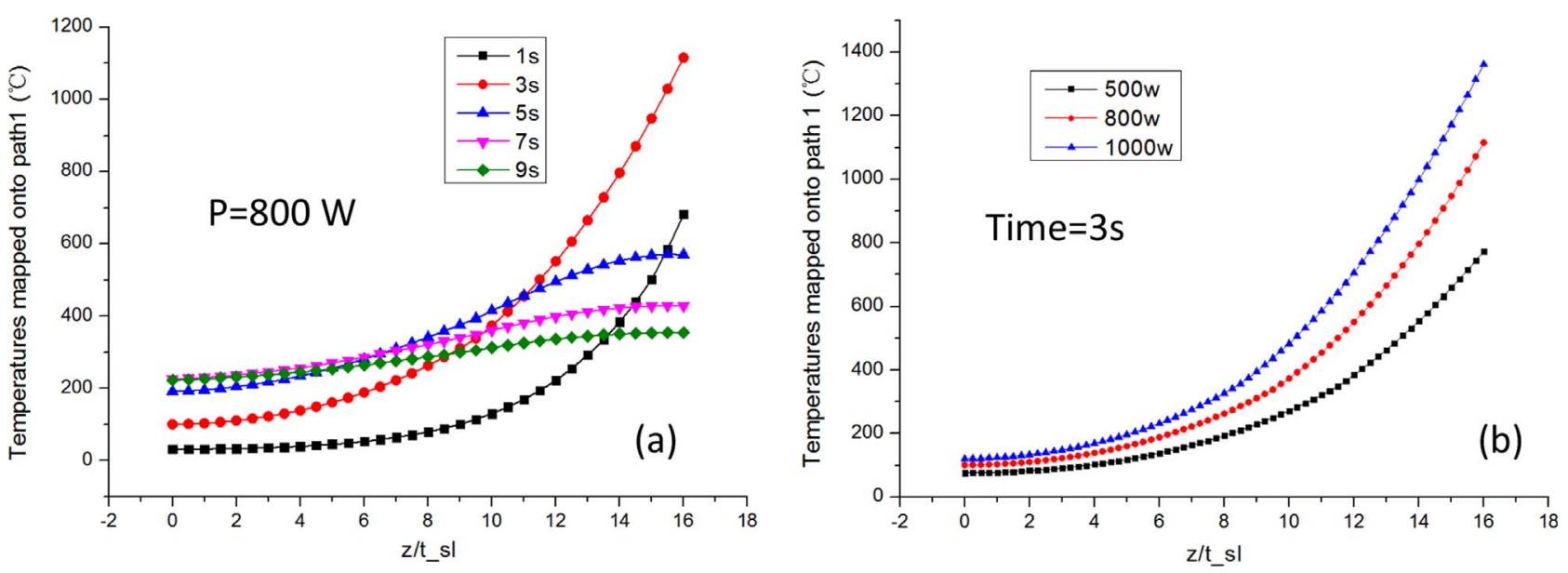

Fig. 11. Temperature for different (a) instants and (b) power mapped onto the path 1 .

The technique of coupling and decoupling of DOF is applied in the modeling to preliminarily simulate the interlaminar cracking of the laminates with the criterion of the normal stress equals to $20 \mathrm{MPa}$ or the absolute magnitude of the resultant shear stress equals to $25 \mathrm{MPa}$. The progressive cracking could be observed around the backward surface in the specimen subjected to the irradiation of Laser with output power 800w as shown in Fig. 21. It is indicated that the interlaminar cracking would arise during the unloading stage and the interface cracks propagate with the cooling of the specimen, which might be partly because that the interlaminar cracks enhance the stress singularity around the crack tip. It is also revealed that the crack surfaces would experience relative sliding under the action of shear stress although the crack opening displacement is not so obvious at some interfaces near the backward surface of the specimen. 

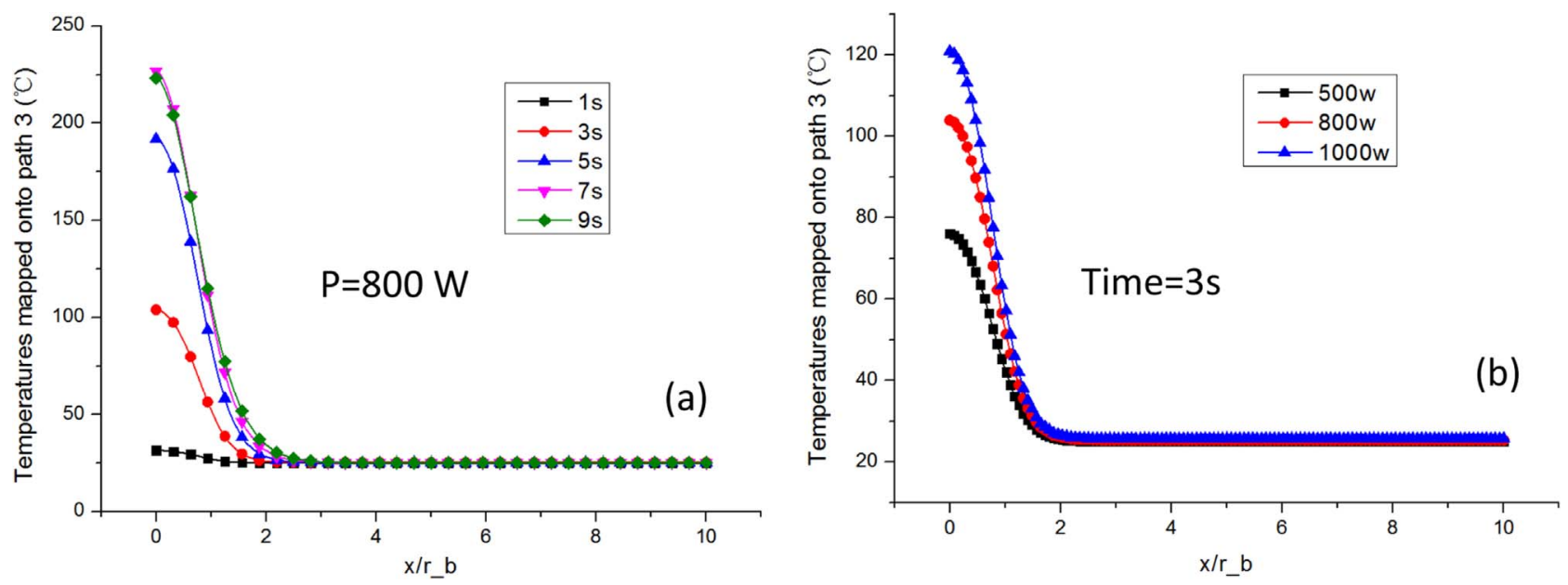

Fig. 12. Temperature for different (a) instants and (b) power mapped onto the path 3.
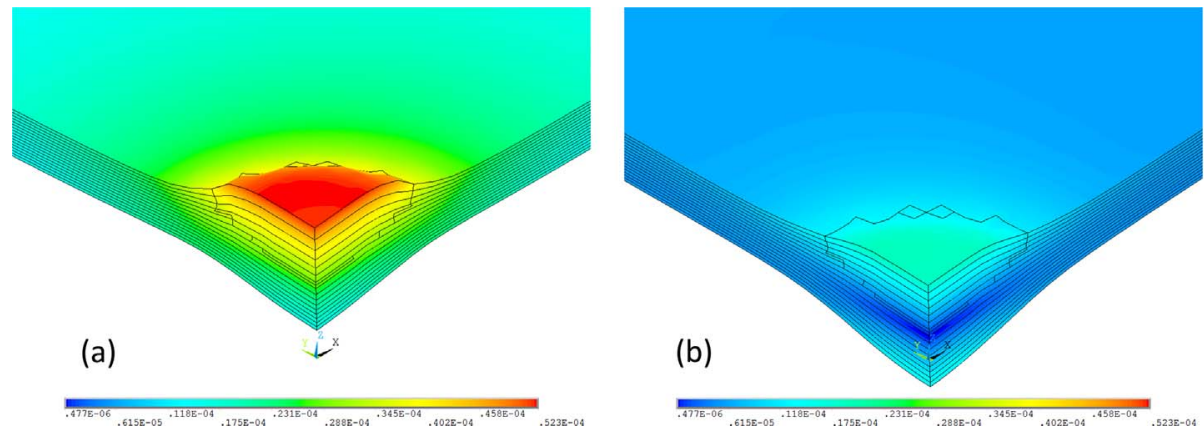

Fig. 13. Total displacement profiles for the case of $P=800 \mathrm{~W}$ at instant (a) $3 \mathrm{~s}$, (b) $5 \mathrm{~s}$ and (c) $7 \mathrm{~s}$.
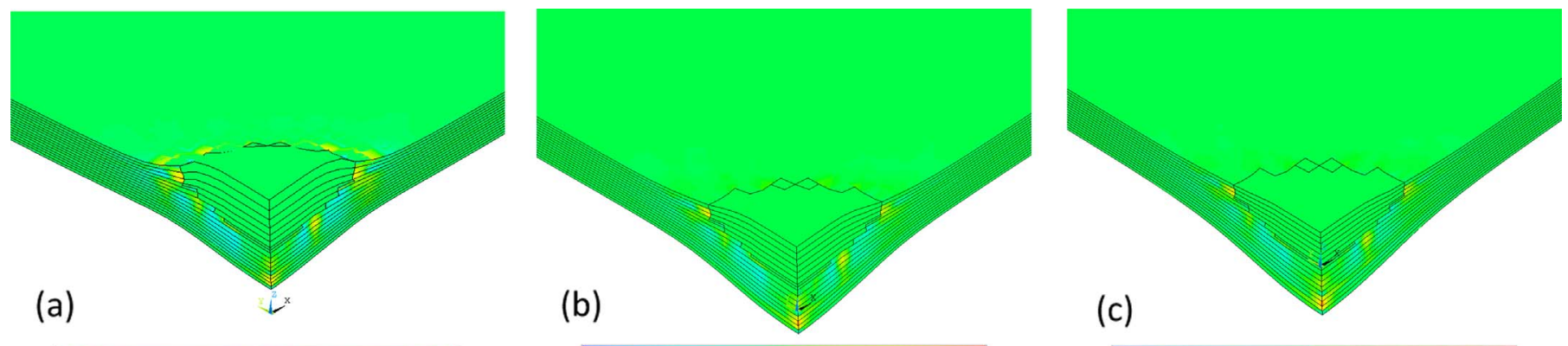

(c)
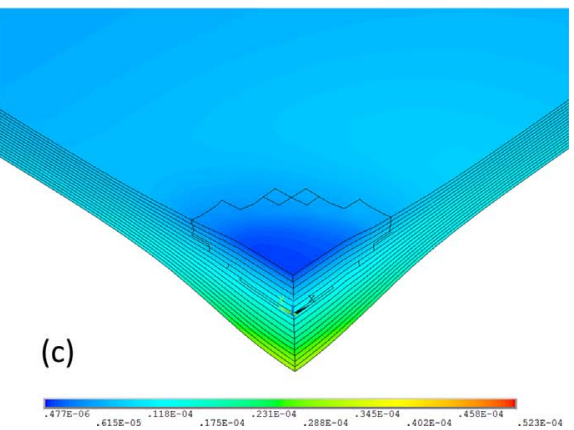

c)

Fig. 14. SZ profiles for the case of $P=800 \mathrm{~W}$ at instant (a) $3 \mathrm{~s}$, (b) $5 \mathrm{~s}$ and (c) $7 \mathrm{~s}$.
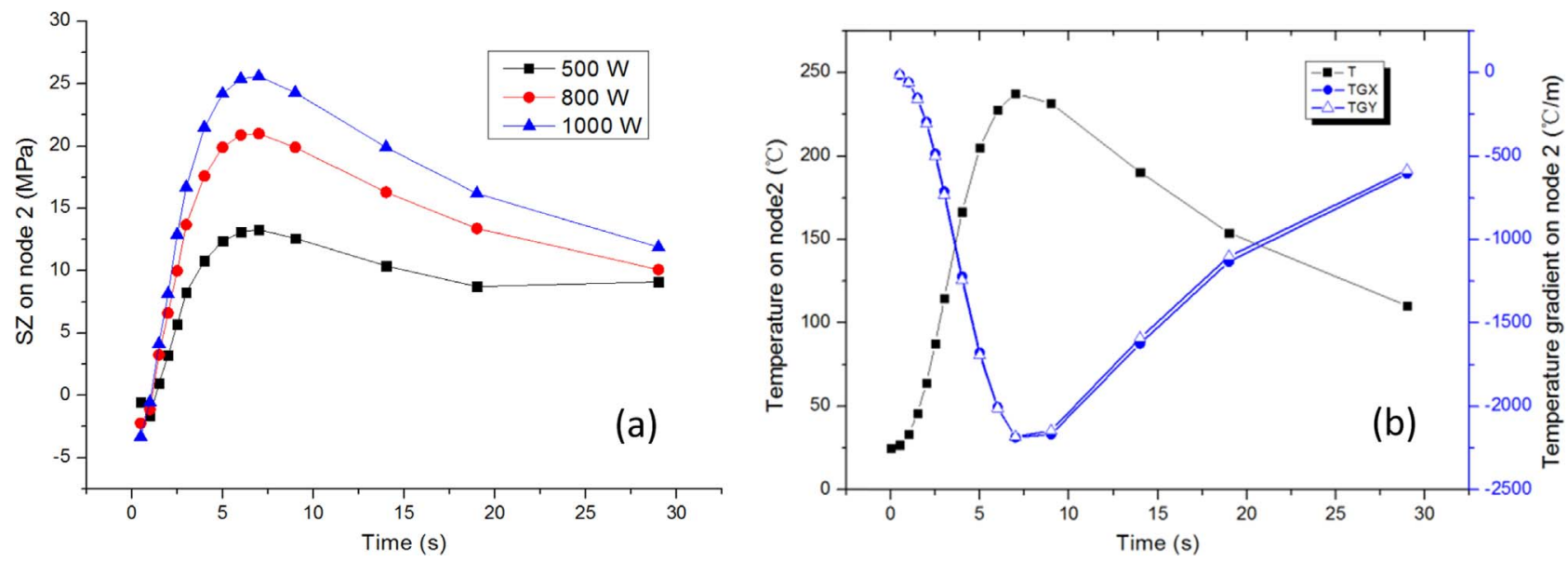

Fig. 15. (a) SZ history (b) temperature and temperature gradient on node 2 . 

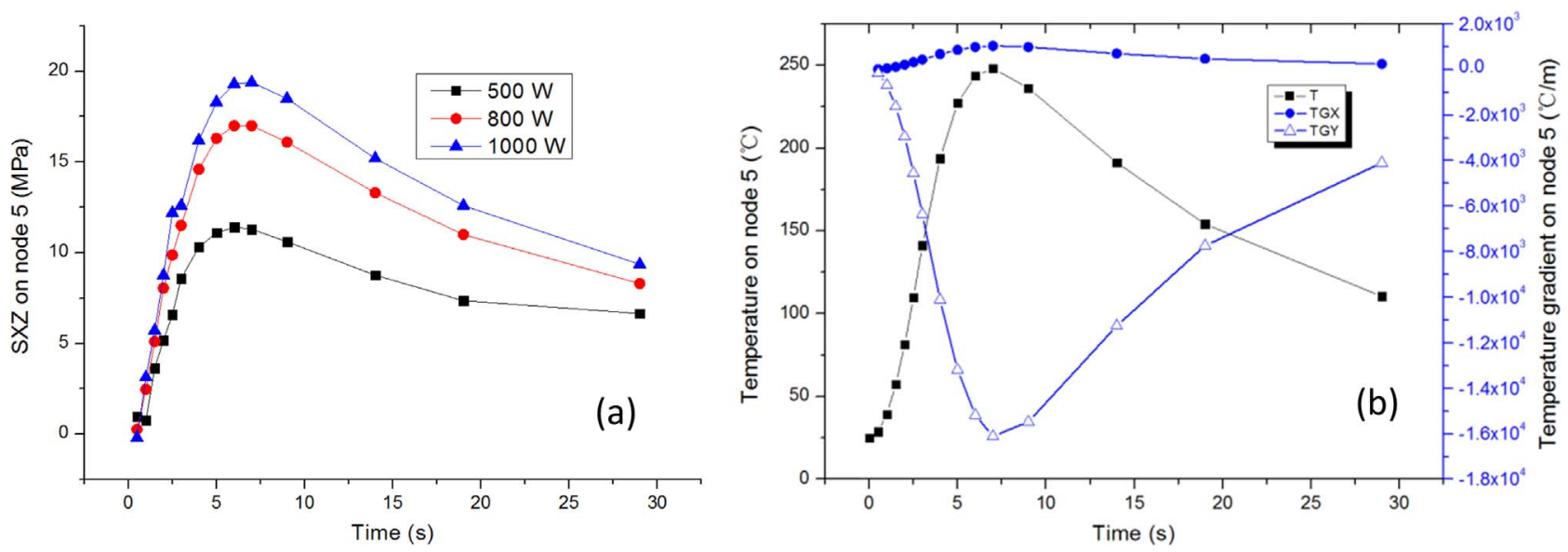

Fig. 16(. a) SXZ history (b) temperature and temperature gradient on node 5 .
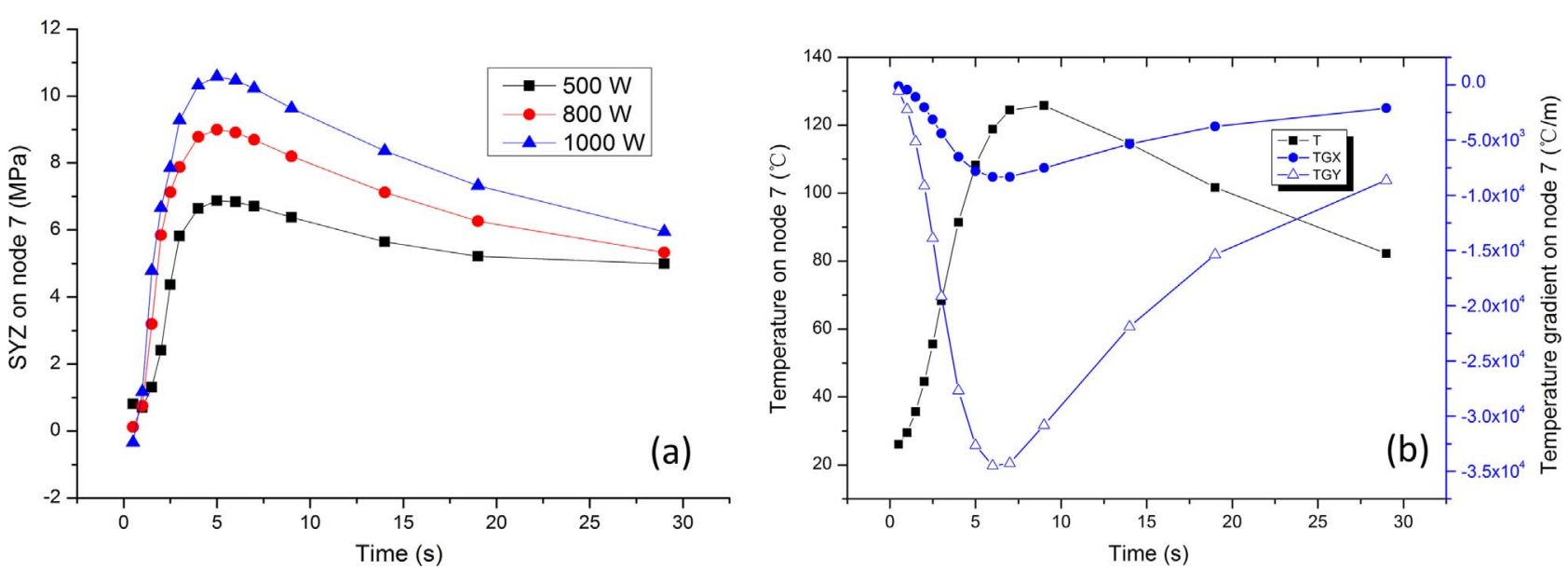

Fig. 17. (a) SYZ history (b) temperature and temperature gradient on node 7.
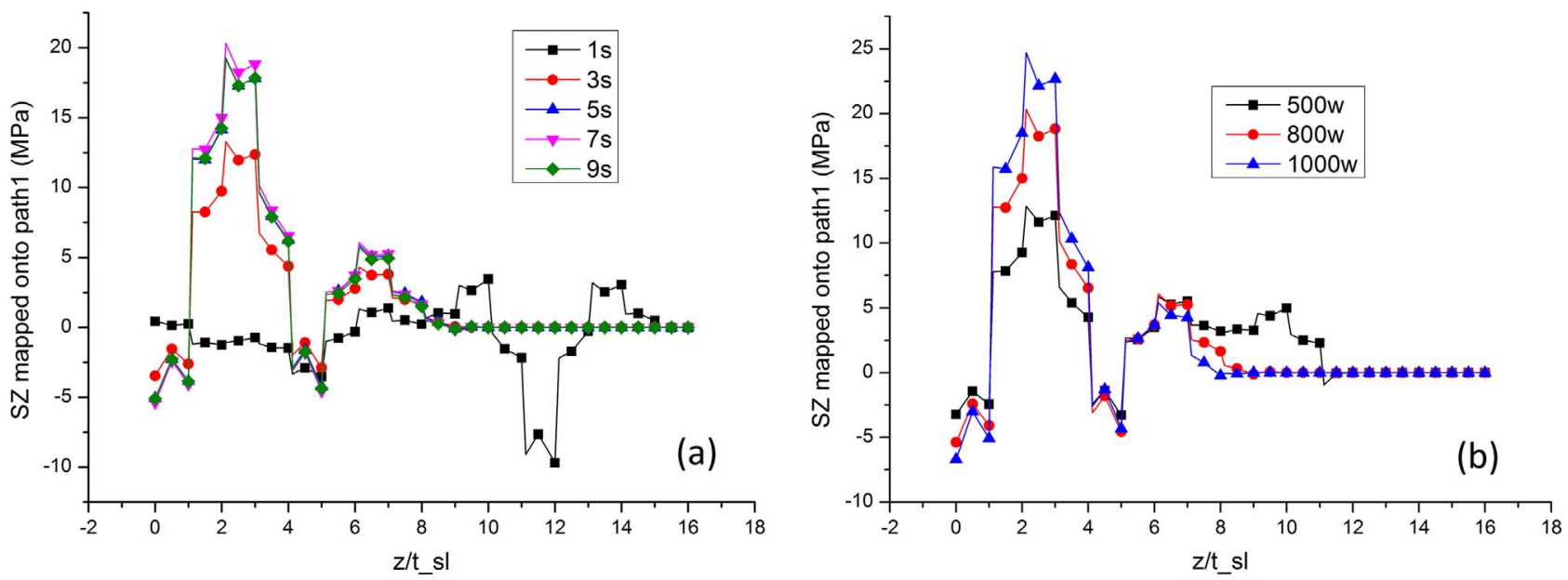

Fig. 18. SZ for different (a) instants and (b) power mapped onto path 1.

\section{Conclusion}

The thermo-mechanical responses of the CFRP laminate to the irradiation by continuous wave laser were investigated experimentally and numerically. In particular, the interlaminar damages induced by the thermal loading were studied. The theoretical results have explained well the experimental outcome.

The experimental results indicate that the ablation would arise in the forward surface layer irradiated by the continuous wave laser due to the pyrolysis of the epoxy matrix. And large interlaminar cracks have been observed, especially around the backward surface of the specimens. 


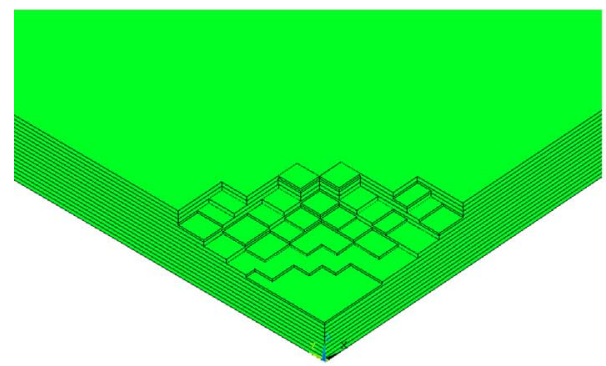

(a) $\mathbf{P}=500 \mathrm{~W}$

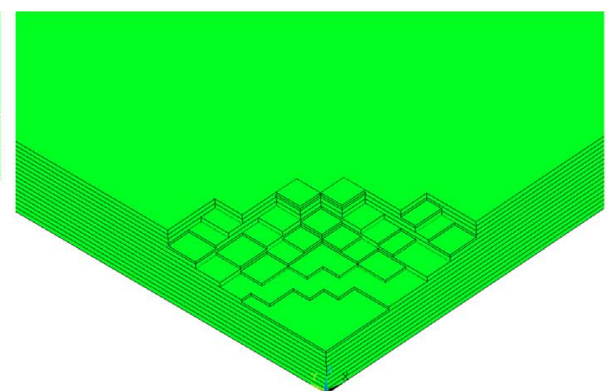

(b) $\mathrm{P}=800 \mathrm{~W}$

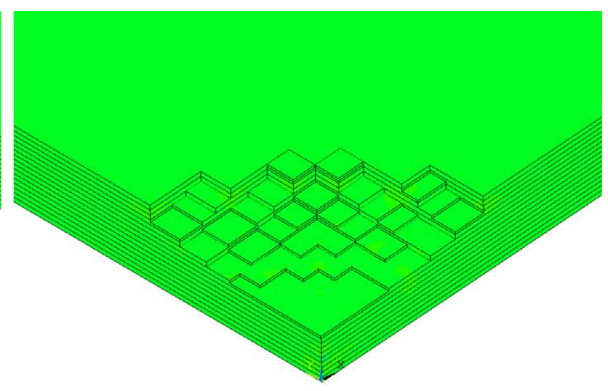

(c) $P=1000 \mathrm{~W}$

Fig. 19. Calculated pyrolyzation morphology for the three cases. (a) $P=500 \mathrm{~W}$ (b) $P=800 \mathrm{~W}$ (c) $P=1000 \mathrm{~W}$.
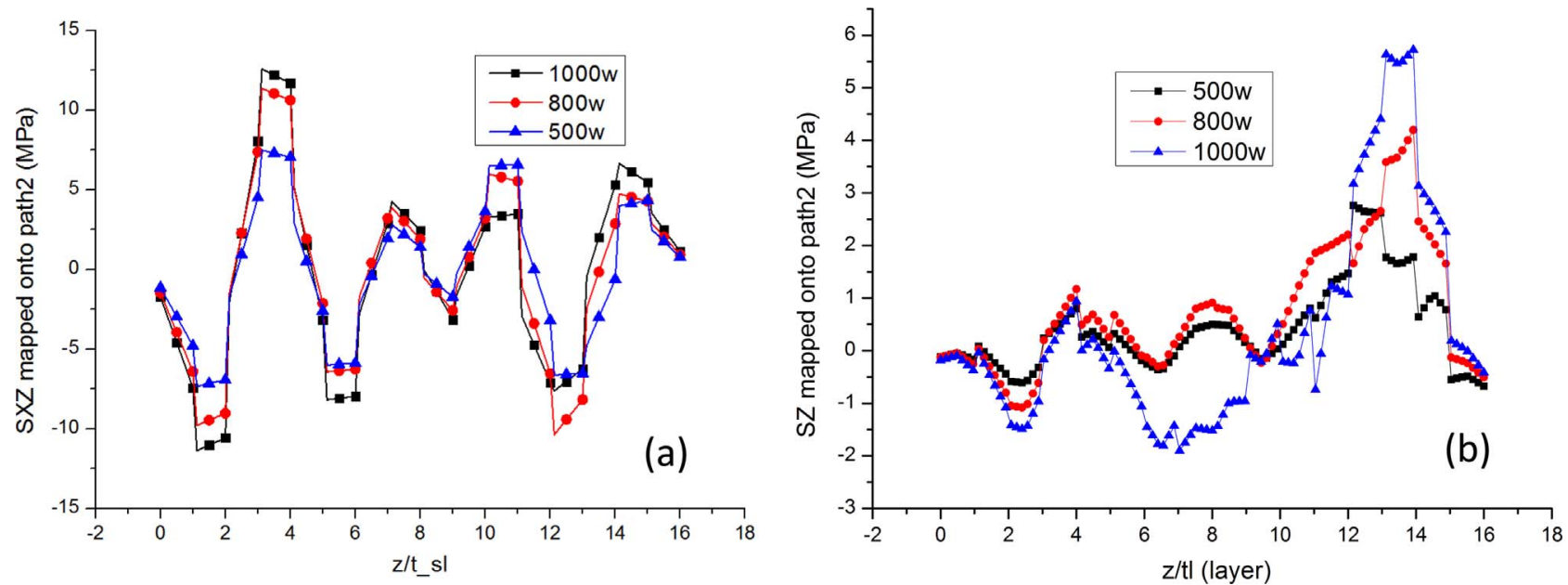

Fig. 20. (a) SXZ and (b) SZ at instant $7 \mathrm{~s}$ mapped onto path2.

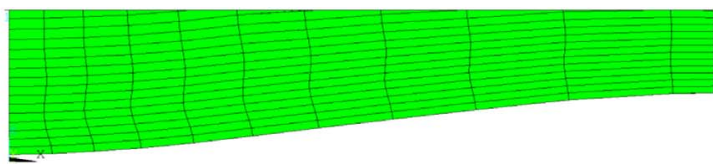

(a)

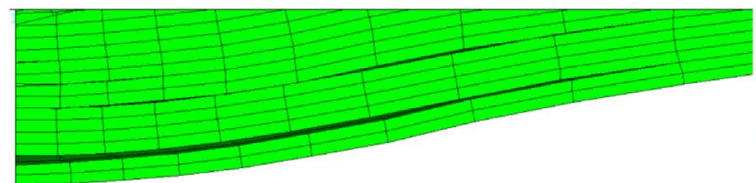

(c)

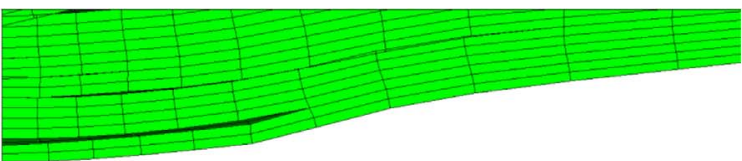

(b)

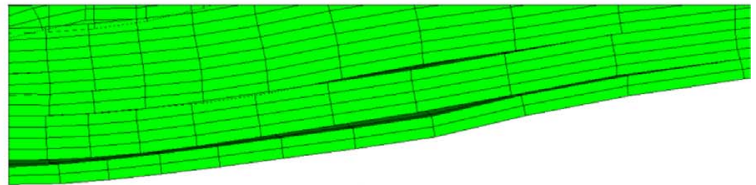

(d)

Fig. 21. Interlaminar cracks at the instants of (a) $3 \mathrm{~s}$, (b) $5 \mathrm{~s}$, (c) $7 \mathrm{~s}$ and (d) $9 \mathrm{~s}$.

The finite element analysis reveals that the peak stresses arise in the cooling stage after the laser beam was removed, when the maximum temperature gradients are developed in the specimens. Moreover, the peak normal stress as well as shear stress arise at the interfaces between the laminae around the backward surface of the specimen, that is why the large interlaminar cracks were observed therein. This is also validated by the preliminary numerical simulation with coupling and decoupling technique of DOF of the interfacial nodes.

\section{Acknowledgment}

This work was supported by the National Natural Science Foundation of China (Grant nos. 11332011 and 11572327). Thanks are also due to Weina Zhao from CAS for the assistance with the experimental operations.

\section{References}

[1] Andersson, F., et al., Design for Manufacturing of Composite Structures for Commercial Aircraft - the Development of a DFM Strategy at SAAB Aerostructures. Variety Management in Manufacturing: Proceedings of the 47th Cirp Conference on Manufacturing Systems; 2014. 17: p. 362-367.

[2] Svensson D, Alfredsson KS, Biel A, Stigh U. Measurement of cohesive laws for interlaminar failure of CFRP. Composites Sci Technol 2014;100:53-62.

[3] Su F, et al. Study of thrust forces and delamination in drilling carbon-reinforced plastics (CFRPs) using a tapered drill-reamer. Int J Adv Manuf Technol 2015;80(5-8):1457-69.

[4] Kim TY, Atluri SN. Interlaminar stresses in composite laminates under out-ofplane shear bending. Aiaa J 1994;32(8):1700-8.

[5] Schiffer A, Tagarielli VL. Predictions of the interlaminar tensile failure of a 
carbon/epoxy composite laminate. Compos Struct 2015;133:997-1008.

[6] Leone C, Genna S, Tagliaferri V. Fibre laser cutting of CFRP thin sheets by multi-passes scan technique. Opt Lasers Eng 2014;53:43-50.

[7] Freitag C, et al. High-speed observation of the heat flow in CFRP during laser processing. Laser Assist Net Shape Eng 2012;7(39):171-8 (Lane 2012).

[8] Weber R, et al. Heat accumulation during pulsed laser materials processing. Opt Express 2014;22(9):11312-24.

[9] Giannadakis K. Varna, J. Effect of thermal aging and fatigue on failure resistance of aerospace composite materials. In: 5th International Eeigm/Amase/ Forgemat Conference on Advanced Materials Research; 2009.

[10] Mlyniec A, et al. The influence of the laminate thickness, stacking sequence and thermal aging on the static and dynamic behavior of carbon/epoxy composites. Compos Struct 2014;118:208-16.

[11] Park JM, et al. Effects of carbon nanotubes and carbon fiber reinforcements on thermal conductivity and ablation properties of carbon/phenolic composites. Composites B-Eng 2014;67:22-9.

[12] Wu CW, Wu XQ Huang CG. Ablation behaviors of carbon reinforced polymer composites by laser of different operation modes. Opt Laser Technol 2015;73:23-8

[13] Ogihara S, et al. Damage mechanics characterization of transverse cracking behavior in high-temperature CFRP laminates. Composites Sci Technol 2001;61(8):1049-55.

[14] Sha JJ, et al. Influence of carbon fiber's surface state on interlaminar shear properties of CFRP laminate. Compos Interfaces 2013;20(8):543-52.

[15] Wang YC, Kodur V. Variation of strength and stiffness of fibre reinforced polymer reinforcing bars with temperature. Cem Concr Composites 2005;27 (9-10):864-74.

[16] Kar KK, et al. Short-term effect of distilled water, seawater and temperature on the crushed and Interlaminar shear strength of fiber reinforced plastic composites made by the newly proposed rubber pressure molding technique. Polym Composites 2008;29(6):670-91.

[17] Meng M, et al. Effects of hygrothermal stress on the failure of CFRP composites. Compos Struct 2015;133:1024-35.

[18] Borstnar G, et al. Interlaminar fracture micro-mechanisms in toughened carbon fibre reinforced plastics investigated via synchrotron radiation computed tomography and laminography. Composites Part a-Appl Sci Manuf 2015;71:176-83.

[19] Armitage PR, Wright CD. Design, development and testing of multi-functional non-linear ultrasonic instrumentation for the detection of defects and damage in CFRP materials and structures. Composites Sci Technol 2013;87:149-56.

[20] Cheng L, Tian GY. Surface crack detection for carbon fiber reinforced plastic (CFRP) materials using pulsed eddy current thermography. IEEE Sens J 2011;11 (12):3261-8.

[21] Bedsole RW, Bogert PB, Tippur HV. An experimental investigation of interlaminar and intralaminar dynamic fracture of CFRPs: effect of matrix modification using carbon nanotubes. Compos Struct 2015;132:1043-55.

[22] Dixit A, Mali HS, Misra RK. Investigation of the thermomechanical behavior of a $2 \times 2$ TWILL weave fabric advanced textile composite. Mech Compos Mater $2015 ; 51(2): 253-64$

[23] Kimura H, et al. Smart structure for suppression of mode I and II crack propagation in CFRP laminates by shape memory alloy TiNi actuator. Int J Fatigue 2006;28(10):1147-53.

[24] Schulte-Fischedick J, et al. The crack development on the micro- and mesoscopic scale during the pyrolysis of carbon fibre reinforced plastics to carbon/ carbon composites. Composites A: Appl Sci Manuf 2007;38(10):2171-81.

[25] de Boer A, van Zuijlen A, Bijl H. Review of coupling methods for non-matching meshes. Comput Methods Appl Mech Eng. 2007;196(8):1515-25.

[26] Rogers KF, Phillips LN, et al. The thermal expansion of carbon fibre-reinforced plastics. J Mater Sci 1977;12(4):718-34.

[27] Takenakaa K, Ichigo M. Thermal expansion adjustable polymer matrix composites with giant negative thermal expansion filler. Composites Sci Technol 2014;104(19):47-51.

[28] Sha JJ, et al. Influence of carbon fiber's surface state on interlaminar shear properties of CFRP laminate. Compos Interfaces 2013;20(8):543-52. 